\title{
Preparation and Characterization of Low-gloss Waterborne Polyurethane Coatings
}

\author{
Liang Zhang \\ School of Materials \\ Beijing Institute of Technology \\ Beijing, China \\ E-mail: frank72072@qq.com
}

\begin{abstract}
In this research, a series of anionic low-gloss waterborne polyurethanes were prepared, and their surface structures were studied. Samples were prepared with terminal hydroxyl polydimethylsiloxane (PDMS), polyethylene glycol (PEG) of different molecular weight, toluene diisocyanate (TDI), dimethylolpropionic acid (DMPA), in the presence of dibutyltin dilaurate (DBTDL) catalyst, neutrallized by triethylamine (TEA). Preparation process was optimized to get better emulsion stability and matting effect of coating. The preparation process is: at $90{ }^{\circ} \mathrm{C}$, react terminal hydroxyl polydimethylsiloxane, polyethylene glycol, toluene diisocyanate and dibutyltin dilaurate catalyst together for $4 \mathrm{~h}$. Cool the performed polymer to $50{ }^{\circ} \mathrm{C}$, then add quantified dimethylolpropionic acid and solvent such as tetrahydrofuran, heat to $70{ }^{\circ} \mathrm{C}$ and react for $2 \mathrm{~h}$. Cool polymer to room temperature, add quantified triethyl-amine and deionized water to make emulsions. Matting aqueous polyurethane under the conditions of $R=1.2$, DMPA mass fraction of 6\%, PEG molecular weight of 1000, PEG / PDMS molar ratio $=1: 3$, catalyst mass fraction of $0.5 \%$, neutralization degree $100 \%$, latex solid content of $20 \%$, gets the best overall performance, $60^{\circ}$ gloss of 3.3 , in line with matting standards.
\end{abstract}

Keywords-Waterborne Polyurethane; Polydimethylsiloxane; Polyethylene Glycol; Copolymerization; Low-gloss

\section{INTRODUCTION}

Waterborne polyurethane uses water as solvent, eliminating the danger of flammable and combustible solvent-based polyurethane in production and transportation. Furthermore, it is environmental friendly and will not harm people's health. Therefore, research on waterborne polyurethane is a hot zone [1]. In the matter of leather fin ishing, waterborne polyurethane has advantages of good air permeability and good moisture-penetrability [2] [3]. In leather products market, the pursuit of natural style and sense of genuine leather is a great trend, so the demand of leather that has a sense of genuine leather and low-gloss is increasing. Matting waterborne polyurethane leather finishing agents can reduce the gloss of leather surface, eliminating plastic sense caused by too bright leather surfaces, form soft, natural, elegant look [4] [5].

Matting performance of coatings mainly depends on appropriately formed surface roughness [6]. Micron roughness on membrane surface makes a strong scattering and diffusion of incident light, and reduces the amount of light reflected into the eyes of people by matting coating surface, so as to achieve the purpose of matting. At present, preparation of matting polyurethane coatings is to add micron-sized silica matting agent [7] into WPU dispersion, but adding inorganic components into the emulsion will reduce system stability and scratch resistance and bending resistance of the coating. US6331582 B1 [8] described a thermally activated coating composition comprising a solvent-based acrylic or polyester binder resin, a colorant and a polyvinyl acetal matting agent. EP0841992 A2 [9] disclosed a low-gloss solvent-based crosslinkable coating composition comprising a comb ination of polar polymers, non-polar poly mer and cross linking agent. US5744522 [10] disclosed a low-gloss powder coating composition comprising acrylic copolymer, aromatic polyester and specific isocyanurate curing agent. However, the solutions above use organic solvents to form dispersion, or add complex organic matting particles.

This article prepared self-emulsifying waterborne matting polyurethane dispersion without using matting agent, with excellent coating matting performance, good emulsion stability, water resistance, scratch resistance, etc., it can be widely used in Polyvinyl chloride (PVC), polyurethane (PU) leather surface finishing.

\section{EXPERIMENT AL}

\section{A. Materials}

Polyethylene glycol (PEG, Mn=400, 600, 1000, 2000), purchased from Xilong Chemical ltd., CP; terminal hydroxyl polydimethylsiloxane (PDMS, $\mathrm{Mn}=2000$ ), purchased from Canada Siltech co., industrial; toluene diisocyanate (TDI), purchased from Bayer co., industrial; dimethylolpropionic acid (DMPA), purchased from Baishun Chemical co., CP; dibutyltin dilaurate (DBTDL), purchased from Xilong Chemical ltd., AR; triethylamine (TEA), purchased from Beijing Chemical Factory, AR; tetrahydrofuran (THF), purchased from Beijing Chemical Factory, AR.

\section{B. Synthesis Procedures}

Add quantified PEG and PDMS into a $250 \mathrm{ml}$ threenecked flask with thermometer, blender, and condenser tube, then dehydrate at $100{ }^{\circ} \mathrm{C}$ in vacuum for $1 \mathrm{~h}$. Cool to $90{ }^{\circ} \mathrm{C}$, add quantified TDI and DBTDL, react for $4 \mathrm{~h}$. Cool to $50{ }^{\circ} \mathrm{C}$, add quantified DMPA and THF, heat to $70{ }^{\circ} \mathrm{C}$, react for $2 \mathrm{~h}$. Cool to room temperature, add quantified TEA to neutralize prepolymer, then add deionized water to make the emulsion.

Pour the emulsion into glass petri dishes at room temperature, wait until it forms a film, and dehydrate the films at $60{ }^{\circ} \mathrm{C}$ in vacuum for $24 \mathrm{~h}$ to get the samples. 


\section{Measurements}

FTIR spectra were recorded on a Nicolet 8700 FTIR spectrometer (Thermo Scientific), using $\mathrm{KBr}$ method, region $4000 \mathrm{~cm}-1 \sim 500 \mathrm{~cm}-1$.

Coating gloss was tested by Sheen $101 \mathrm{~N} 60^{\circ}$ vancometer, according to ISO 2813:2014 < Paints and varnishes - Determination of gloss value at 20 degrees, 60 degrees and 85 degrees $>$.

Isocyanate content was tested according to DIN EN ISO 11909-2007 < Binders for paints and varnishes -Polyis ocyanate resins - General methods of test $>$.

SEM photos of polyurethane coatings were taken by a Hitachi TM3000 SEM, magnification ratio s were 100, 1000,9000 .

\section{RESULTS ANDDISCUSSION}

\section{A. Material selection}

Materials of self-emulsifying waterborne polyurethane dispersions mainly include isocyanates, oligomer polyols, chain extenders, neutralizing agents, catalys ts and solvents. Depending on the type of hydrophilic group in the molecular chain, polyurethanes can be divided into anionic, cationic, amphoteric and nonionic.

Oligomer polyols generally include polyether polyols and polyester polyols. PDMS backbone is composed of highly flexible silicon-oxygen bond, has low surface energy, good hydrophobility, oxidation resistance and thermal stability. Coatings have excellent and unique surface properties. PEG chain segment contains a large number of ether bonds, and has good crystallinity and hydrophilicity. Polyether segments may provide good emulsion stability, to constitute non-ionic self-emulsifying polyurethane. PEG segments and PDMS segments will interact in the polyurethane surface to form micro rough structure, resulting in matting effect, so we choose PDMS and PEG as the polyol component.

Isocyanates mainly include aromatic isocyanates, aliphatic isocyanates, and alicyclic isocyanates. The aromatic isocyanates have generally higher reaction activity, which will help reacting with the low-reactivity PDMS, so we choose TDI as material.

Commonly used DMPA is chosen as hydrophilic chain extender, which may help constitute the anionic selfemulsifying waterborne polyurethane and increase the molecular weight of the polyurethane.

DBTDL is chosen as catalyst, to accelerate the reaction rate.

TEA is chosen as neutralizer, to form hydrophilic structure with DMPA carboxy.

THF is chosen as solvent, of which boiling point range fit the reaction temperature. Series of experiments showed that commonly used acetone, methyl ethyl ketone as a solvent can cause precipitation of prepolymer at the end of reaction.

\section{B. Confirmation of synthesis conditions}

Terminal hydroxy ls of PDMS react slower than normal polyols with TDI. Reactions were carried at different temperatures, to confirm reaction reaches end, content of isocyanates in prepolymer were measured over time.

Fig. 1 showed remaining content of isocyantes of prepolymerization at different temperatures. At $70^{\circ} \mathrm{C}$ or $80^{\circ} \mathrm{C}$, there were more isocyantes remaining than $90^{\circ} \mathrm{C}$ after 4 h. At $90^{\circ} \mathrm{C}$, is ocyantes content reached theoretical value after $4 \mathrm{~h}$. At higher temperature, more side reactions were initiated and caused yellowing of prepolymer. Therefore, prepolymerazation should be held at $90^{\circ} \mathrm{C}$ for 4h. Chain extender DMPA reacted too fast with is ocyantes at high temperature, so before adding DMPA, prepolymer should be cooled to $50^{\circ} \mathrm{C}$ and diluted with solvents to avoid crosslinking. After this, heat prepolymer to $70^{\circ} \mathrm{C}$ for $2 \mathrm{~h}$ for reaction.

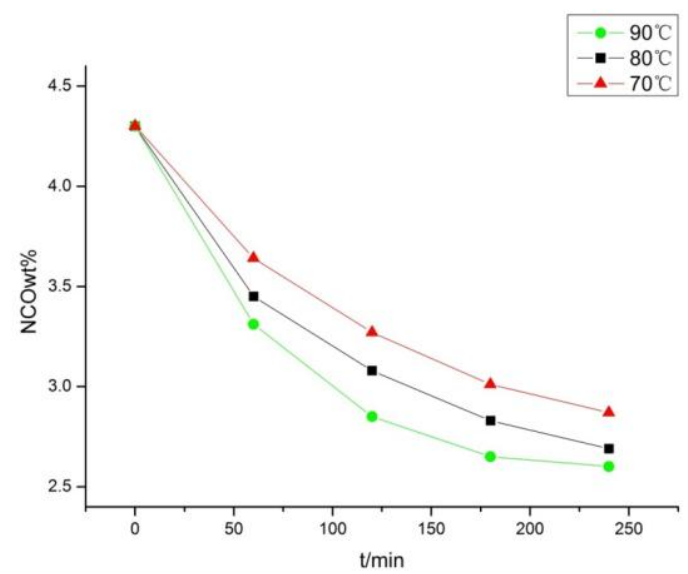

Figure 1. Remaining content of isocyantes of prepolymerization at different temperatures

DMPA content in PU has great influence on hydrophilicity of WPU and stability of dispersions. TABLE 1 showed influence of DMPA on WPU properties. When DMPAwt $\%$ is $\leq 5 \%$, PU dispersions layer is formed due to lack of hydrophilicity. When DMPAwt $\%$ is $\geq 6 \%$, PU dispersions are sTABLE. However, as DMPAwt $\%$ increases, matting effect of PU coatings dropped significantly. When DMPAwt\% increases, length of PDMS segments and PEG segments between carbamates in polymer chain will become shorter, so it is harder for PEG and PDMS to interact on the surface. Distribution density of micro rough structures decreases and matting effect is worse. Therefore, DMPAwt $\%$ should be $6 \%$.

$R$ value is ratio of isocyantes to hydroxyl/amino in reaction. In this article, $\mathrm{R}$ of prepoly mer is above 1.0, so there will be some is ocyantes left when emulsifying. $R$ value influences molecular weight of PU, and the amount of water molecules reacting with isocyantes when emulsifying, thus forms uramidos in PU chain. When R value is high, molecular weight of prepolymers is small, product has more uramidos and coatings are harder. TABLE 2 showed influence of $\mathrm{R}$ value on WPU properties. In this article, when $\mathrm{R}=1.2$, ratio of hard segments to soft segments was appropriate, stability of dispersions was good. No significant influence on matting effect was observed when $\mathrm{R}$ value changed.

Compatibility of PEG and PDMS is poor. After copolymerization, interaction of segments formed micro rough structures on the surface of coatings. As the ratio of PDMS rises, the quantities of rough structures on the surface increase. The distribution density of rough 
structures also increases, and thas improved the matting effect.

TABLE I. INFLUENCE OF DMPA ON WPU PROPERTIES

\begin{tabular}{ccc}
\hline $\begin{array}{c}\text { DMPA weight } \\
\text { percentage/\% }\end{array}$ & $\begin{array}{c}\text { Stability of } \\
\text { dispersions }\end{array}$ & $\begin{array}{c}\text { Gloss of } \\
\text { Coatings }\end{array}$ \\
\hline 5 & Layered & 5.8 \\
6 & STABLE & 3.3 \\
7 & STABLE & 12.6 \\
8 & STABLE & 42.6 \\
9 & STABLE & 43.2 \\
\hline
\end{tabular}

TABLE II.

INFLUENCE OF R VALUE ON WPU PROPERTIES

\begin{tabular}{ccc}
\hline R value & $\begin{array}{c}\text { Stability of } \\
\text { dispersions }\end{array}$ & $\begin{array}{c}\text { Glos of } \\
\text { coatings }\end{array}$ \\
\hline 1.0 & Sediment & 2.6 \\
1.1 & Sediment & 2.4 \\
1.2 & STABLE & 3.3 \\
1.3 & STABLE & 3.3 \\
\hline
\end{tabular}

When PEG content is zero, mic ro rough structures cannot form on the surface of coatings. This will lower the matting effect of the coating. Moreover, PEG segments are hydrophilic, they can improve the stability of dispersions. TABLE 3 showed the influence of PEG/PDMS molar ratio on WPU properties. In this article, when PEG/PDMS $=1: 3$, WPU dispersion stability and coating matting effect both have good performances.

TABLE III. INFLUENCE OF PEG/PDMS MOLAR RATIO ON WPU PROPERTIES

\begin{tabular}{ccc}
\hline PEG/PDMS & $\begin{array}{c}\text { Stability of } \\
\text { dispersions }\end{array}$ & $\begin{array}{c}\text { Gloss of } \\
\text { coatings }\end{array}$ \\
\hline $1: 2$ & STABLE & 17.9 \\
$1: 3$ & STABLE & 3.3 \\
$1: 4$ & STABLE & 3.3 \\
\hline
\end{tabular}

Interactions of PEG and PDMS segments are significantly related to segment length. Difference of segment length of PEG and PDMS will influence the distribution of hydrogen bonds formed near the surface, thus influence crystallization and distribution density of micro rough structures.

TABLE 4 showed influence of PEG molecular weight on WPU properties. In this article, PDMS molecular weight is 2000, when PEG molecular weight is 1000 , coating matting effect is significantly better than group of 400, 600 and 2000.

TABLE IV. INFLUENCE OF PEGMOLECULAR WEIGHT ON WPU PROPERTIES

\begin{tabular}{ccc}
\hline $\begin{array}{c}\text { PEG } \\
\text { molecular } \\
\text { weight }\end{array}$ & $\begin{array}{c}\text { Stability } \\
\text { ofdispersions }\end{array}$ & $\begin{array}{c}\text { Gloss of } \\
\text { coatings }\end{array}$ \\
\hline 400 & STABLE & 46.6 \\
600 & STABLE & 17.9 \\
1000 & STABLE & 2.7 \\
2000 & STABLE & 12.4 \\
\hline
\end{tabular}

\section{Characterization}

FTIR spectra in Fig. 2 showed that the absorption peak of the -NCO group did not appear around $2270 \mathrm{~cm}^{-1}$, this meant all isocyanates had reacted with hydroxyl groups.
The absorption peak of the $\mathrm{N}-\mathrm{H}$ group appeared at 3300 $\mathrm{cm}^{-1}$, the absorption peak of the $\mathrm{C}=\mathrm{O}$ group appeared at $1727 \mathrm{~cm}^{-1}$, this meant the coating contain carbamates that indicated polyurethane existed. The deformation vibration peak of the C-H groups appeared at $1260 \mathrm{~cm}^{-1}$, and stretching vibration absorption peak at 2850-2960 $\mathrm{cm}^{-1}$. The stretching vibration peak of the $\mathrm{Si}-\mathrm{O}-\mathrm{Si}$ groups appeared at $1097 \mathrm{~cm}^{-1}$, the stretching vibration peak of the Si-C group appeared at $800 \mathrm{~cm}^{-1}$. This meant PDMS segments existed in the PU molecular chain. Peaks above proved that target product had been synthesized.

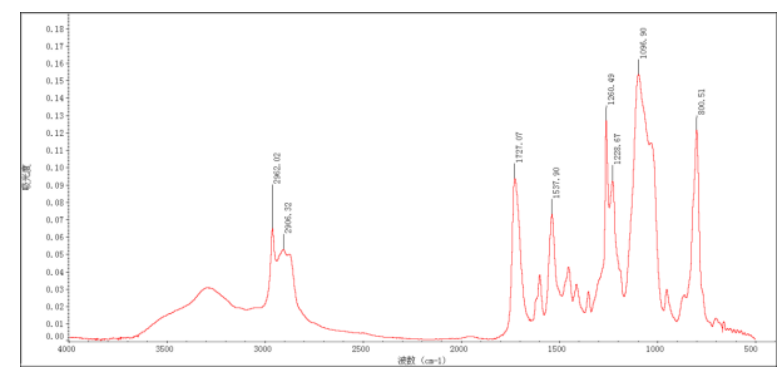

Figure 2. FTIR spectra of copolymerized matting WPU

Fig. 3(A) showed the micro rough structures on the coating surface. Cracks of micrometer can be observed on every coating sample that had matting effect. Micrometer rough structures can scatter incident light well and were a source of matting effect. As the cracks on the surface increases, the matting effect of the coating is better.

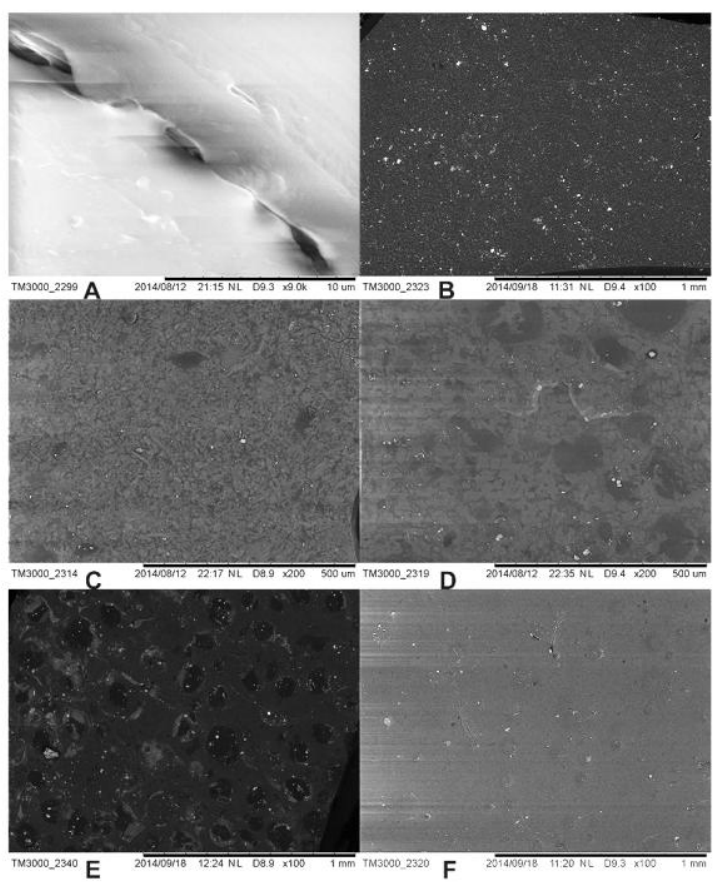

Figure 3. (A) micro rough structures on the coating surface; (B)(F)PEG/PDMS=1:1-1:5 SEM photos of the coating surface.

When $\mathrm{R}=1.2$, DMPAwt $\%=6 \%$, PEG molecular weight $=1000, \mathrm{PEG} / \mathrm{PDMS}=1: 1$, we could distinguish dark area from light area on the coating surface. Dark area and light area equals in area. When PEG/PDMS $=1: 2$, the dark area declined and the light area grew. The dark area formed irregular strip structures in the light area. When 
PEG/PDMS=1:3, the dark area declined and began to gather. When PEG/PDMS $=1: 4$, the dark area declined continuously and the dark area was surrounded with the light area, forming sea-island structures. When $\mathrm{PEG} / \mathrm{PDMS}=1: 5$, the dark area declined and it was hard to observe. Numbers of dark pixels and light pixels were calculated by image processing software, TABLE 5 showed dark area/ light area of SEM photos as PEG/PDMS changed. We found that PEG/PDMS was relevant to dark area/ light area. We could infer that dark area presented PEG aggregation phase and light area presented PDMS aggregation phase. This indicated that PDMS segments and PEG segments had macroscopic phase separation on the coating surface.

TABLE V. DARK AREA/LIGHT AREA OF SEM PHOTOS AS PEG/PDMS CHANGED

\begin{tabular}{crcc}
\hline $\begin{array}{l}\text { PEG/PD } \\
\text { MS }\end{array}$ & $\begin{array}{c}\text { Dark } \\
\text { area/Pixels }\end{array}$ & $\begin{array}{c}\text { Light } \\
\text { area/Pixels }\end{array}$ & $\begin{array}{c}\text { Dark/Li } \\
\text { ght area }\end{array}$ \\
\hline $1: 1$ & 147824 & 156236 & $1: 1.057$ \\
$1: 2$ & 105132 & 200788 & $1: 1.908$ \\
$1: 3$ & 81896 & 220184 & $1: 2.688$ \\
$1: 4$ & 61151 & 247830 & $1: 4.049$ \\
$1: 5$ & 49376 & 253984 & $1: 5.155$ \\
\hline
\end{tabular}

\section{CONCLUSIONS}

WPU matting dispersions were prepared by prepolymer method. The PU coating molecular structure was characterized with FTIR, the surface topography was characterized with SEM. Large quantities of micro rough structures were observed, indicating the coatings prepared coincided with the matting principle.

\section{REFERENCES}

[1] Xu G. Waterborne Polyurethane Materials[M]. Chemistry Industry Press, 2007.

[2] Zhang J. Waterborne Polyurethane Research Progress[J]. Chemistry and Adhesives, 2010 (5): 58-62.

[3] Li J, Zheng W, Zeng W, et al. Structure, properties and application of a novel low-glossed waterborne polyurethane[J]. Applied Surface Science, 2014, 307: 255-262.

[4] Li Chuanhong, Cao Zhaoyun. Study on Aqueous Polyurethane Top Matting Oil for Leather[J]. Leather Chemicals, 2006, 23(1): 19-22.

[5] Zhang Xiaolei, Zhang Zhe. Principle and Synthesis of Leather Matting Finishing Agent[J]. China Leather, 2007, 36(1): 18-21.

[6] Jin Chao, Li Weishan, Yang Xinhong. Matting Principle and Application of Coatings[J]. Guangdong Chemical Industry, 2003, 6 : 31-33.

[7] Zhang Yi, Chen Feifei. Study on Application of Matting Agent Silicon Dioxide in Aqueous Paints[J]. Shanghai Coatings, 2011, 49 (6): 7-11.

[8] Augustin T. Chen, Paul E. Kestyn, Hong Zhao. Low gloss coating[P]. US6331582 B1, 2001-12-18.

[9] Christian Lesage. Surface treatment method for skin-contacting metallic objects[P]. EP0841992 B1, 2000-03-22.

[10] Szu-Ping Lu, Paul J. Prucnal. Low gloss coating compositions[P]. US5744522 A, 1998-04-28.

[11] DIN EN ISO 11909-2007. Binders for paints and varnishes Polyisocyanate resins - General methods of test[S]. 2007-05. 